\title{
UTILIZATION OF CELLULOSE NANOFIBERS AND CATIONIC POLYMERS TO IMPROVE BREAKING LENGTH OF PAPER
}

\author{
PEJMAN REZAYATI CHARANI and MOHAMMAD HADI MORADIAN \\ Department of Natural Resources, Behbahan Khatam Alanbia University of Technology, \\ Behbahan, Iran \\ \Corresponding author: P. RezayatiCharani, rezayati@bkatu.ac.ir
}

Received August 11, 2017

\begin{abstract}
One of the key properties of paper is its breaking length, which is usually controlled in many paper products. To achieve this, several natural and synthetic polymers are used in paper industries in accordance with paper grades and customer needs. In this study, the combination of cationic starch (CS) and/or polyacrylamide (CPAM) as common additives, and cellulose nanofibers (CNFs), were added to a short-fiber pulp suspension to investigate the reinforcement effects and to compare such properties with those of paper prepared with $20 \%$ softwood long-fiber. The breaking length was measured on the prepared handsheets. The results showed that adding $1 \% \mathrm{CS}$ significantly improves paper breaking length, which was well comparable to the handsheets reinforced with $15 \%$ softwood pulp. The results showed that adding less CS $(0.5 \%)$ along with $3 \%$ CNFs significantly increased the paper breaking length, while reducing process difficulties associated with CS. The same result was also achieved adding 3\% CNFs along with $0.03 \%$ CPAM. Furthermore, a triple system of CNFs, CS, and CPAM additives significantly enhanced the paper breaking length and surpassed the breaking length of paper made with $20 \%$ softwood pulp. Using this triple system led to the least changes in handsheet thickness as well. Therefore, this triple system of additives can replace softwood pulp, thereby significantly expanding the spectrum of paper products for the countries with limited softwood pulp sources.
\end{abstract}

Keywords: papermaking, breaking length, cellulose nanofibers, cationic starch, cationic polyacrylamide

\section{INTRODUCTION}

Due to the growing demand for paper and board, researchers have always tried to find affordable solutions, by applying different combinations of lignocellulosic materials and additives to produce valuable paper products. Lack of long fiber lignocellulosic resources in some countries, such as Iran, and the necessity to produce high quality and competitive products has always remained a challenge. Therefore, different chemical additives, such as starches, polymers and resins, or imported long fibers have been applied. For example, Mazandaran Wood and Paper Industries and Pars Papermaking Factory, two of the most important paper mills in Iran, have been adding about 15-20\% imported softwood pulp as long fibers to improve their paper strengths. In addition, most producers of paper from recycled paper in Iran, such as Atrak Factory, are adding cationic starch (CS) to improve the physical and mechanical properties of paper products. The challenge is to maintain competitive physical and mechanical properties of paper. Obviously, using imported long fibers increases production expenses and is a limiting issue because of several financial factors. Also, using reinforcement additives increases the operating costs and has limited effects on paper strength. Based on the literature, the most common paper strengthening additives are starch $^{1-6}$ polyacrylamides ${ }^{3}$ and cellulose nanofibers (CNFs). ${ }^{7-12}$

Starch is the most common and economical additive that increases paper strength, compared to the other conventional resins. ${ }^{6}$ Starch is also a main component in the food industry and this makes a competitive demand and sometimes limited availability or periodic price variability for the use in the paper industry. As a result, other synthetic additives are introduced. Depending on the source of starch (potato, wheat, corn and

Cellulose Chem. Technol., 53 (7-8), 767-774(2019) 
tapioca), two kinds of starches exist: amylose and amylopectin. It is a polysaccharide, structurally similar to cellulose, and can be ionized with cationic agents for bonding with anionic material surfaces. The amount of ionization, the degree of substitution (DS), is $0.02-0.1$ and is usually in the range of $0.03-0.06 .{ }^{13}$ Since there is more interest in the industries for closed loop water systems, there is more need for starch with a higher degree of substitution. Native and anionic starches are also used in the sizing section of paper industries, ranging from 0.5 to $1.5 \%$, enhancing paper stiffness by about 20 to $25 \%$. However, the use of native and anionic starches is diminishing because of paper remoisturizing, which incurs extraoperating costs for drying. Using CS, on the other hand, eliminates the paper remoistening problem. Nevertheless, it is more expensive than native starches. CS is usually added to thick pulp suspensions as a reinforcement agent and sometimes to diluted pulp suspensions as a retention aid. It is usually added in amounts less than $1.5-2 \% .^{13} \mathrm{CS}$ acts according to three mechanisms: 1) increases bonding surface, making denser paper, 2) strengthens bonding among fibers and 3) decreases stress concentration in paper. ${ }^{14}$ Indeed, similar to microfiber and nanofiber, CS has sufficient molecular size to span inter-fiber distances and tends to form hydrogen bonds with cellulosic materials. It obviously increases the number of low energy bonds, as van der Waals forces and hydrogen bonding with cellulosic materials, and functions as a paper strengthening agent, improving the breaking length of paper.

Nevertheless, using cationic starch increases the operating costs because it needs a system of preparation. In addition, such polymers increase waste water treatment costs because of increased biological oxygen demand, ${ }^{15}$ foaming, and problems of slime and sedimentation on the paper production equipment and also interferences in drainage and paper machine runnability. ${ }^{16-17}$ Therefore, some manufacturers are interested in using artificial polymers such as polyacrylamide.

The first use of cationic synthetic polyelectrolytes as flocculants in the industries dates back to several decades ago. They are used as wet-end additives that can retain cellulosic fines and fillers in the paper industries. The most common kind of these materials is the cationic polyacrylamide, CPAM, a copolymer of acrylamide and cationic trimethyl ammonium chloride monomers. All CPAM polymers have an average molecular weight of $4-5 \mathrm{~g} / \mathrm{mol}$ and a degree of substitution (DS) of 0.02, 0.04, 0.14 and 0.27 , with a charge density of $0.26,0.52,1.6$ and 2.6 meqv/g, respectively. ${ }^{18}$ These materials are used as flocculants in the wet-end paper manufacturing process on the paper machine wire. ${ }^{19}$ The mechanism of action of these highdensity polymers is to make polymer bridges on solid surfaces and improve the specific bonding strengths. ${ }^{20}$ These agents keep the paper bulk, while increasing the bonding ability, whereas in the common pulp refining process, the paper bulk decreases and density and bonding surface increase. ${ }^{14}$ It is also reported that high-density polyacrylamides improve paper dry strengths more than low-density ones. However, using too much high-density polyacrylamides causes extraflocculation, uneven and mottled paper formation and a drop in final paper strengths. ${ }^{13}$ Generally, CPAM plays the role of a flocculating agent and retains negative load fines in the pulp suspension. These fines include fiber particles, fillers and CNFs and are expected to improve most of the paper properties if the flocculation and paper formation would be controlled in a good proportion.

Using CNFs as a new additive to reinforce paper has been considered in the recent years. $^{7,8,11,12,21,22}$ According to research reports, using CNFs with CPAM retention aid makes stronger paper, and this reinforcement varies when using different CNFs. CNFs have a high aspect ratio and $\mathrm{L} / \mathrm{D}$ ratio and therefore, it is used in wet and dry sections. ${ }^{23}$ Indeed, these nanofiber additives locate in the space among fibers and act as a connecting agent ${ }^{24}$ in paper structure, filling the empty distance among them, hence increasing the number of fiber-fiber bonds via an entangled network, and as a result, boost the hydrogen bonding during consolidation and drying of the fibre network. Additionally, the strong connections between the fibers and CNF networks make the final paper very strong. ${ }^{25}$

In addition, nanofibers have small diameters, which make smoother paper surface and better printability and increases final paper density. ${ }^{26}$ The possibility of substituting long fibers with CNFs was investigated recently in order to improve the breaking length of paper made from softwoods. ${ }^{7,11}$ The results of this research showed that, instead of adding 30\% Kraft pulp made from pine fibers, it is possible to use $7 \% \mathrm{CNFs}$, and still keep the paper breaking length. Other assessments revealed that the drainage rate, 
brightness, breaking length and density of paper increase if CNFs are added to the pulp, but it has a reverse effect on the paper bulk. Although CNFs improve paper breaking length, tear strength drops a little. According to this research, adding $1 \%$ CNFs made from bagasse, along with $0.1 \%$ CPAM as retention aid, improved the paper physical and mechanical properties, without significant drop in drainage rate. ${ }^{8}$ Hence, reducing the drainage rate in the wet-end section is one of the limiting factors of using CNFs. CPAM can improve the drainage rate, but it requires an adjustment dose to avoid process issues. ${ }^{27}$

In this research, the use of CS-CNFs, CPAM$\mathrm{CNFs}$ and CS-CNFs-CPAM additives was investigated to improve the breaking length of hardwood bleached Kraft pulp to replace all or a part of the softwood pulp.

\section{EXPERIMENTAL}

\section{Materials}

Unbleached pulp was prepared from a hardwood mixture in Iran Wood and Paper Industries Inc., Chouka, located in Rezvanshahr, Gilan province. The pulp freeness and Kappa number were $400 \mathrm{~mL}$ CSF and 65 , respectively. Imported softwood long fiber pulp, obtained from Pars Paper Mill (Iran), was also added. CNFs made from softwood alpha-cellulose by the super-grinding method were supplied by Nano Novin Polymer Inc. The specifications of CNFs are shown in Figure 1. The diameter and length of CNFs reported by the producer were $32 \pm 10 \mathrm{~nm}$ and $\sim 10$ micrometers, respectively. Cationic starch (CS) was supplied by Glucosan Inc. and the cationic polyacrylamide (CPAM) by Eka Chemicals (Bohus, Sweden). The commercial name of the latter is PL 15 20, with 7 million $\mathrm{g} / \mathrm{mol}$ molecular weight and $20 \%$ molecular charge density, classified as cationic polymer with high molecular weight and low electrical charge. The $\mathrm{pH}$ of the cationic starch was about 6 , the DS about $0.035 \mathrm{~mol} / \mathrm{mol}$, protein content of $1.5 \%$, nitrogen of $0.25 \%$, ash of $2 \%$, and moisture content of $11 \%$ on dry weight basis.

\section{Methods \\ Chemicals and measurements}

The pulp was bleached with sodium hydroxide and then sodium hypochlorite in four stages of EHEH, to attain pulp brightness of 75 (Table 1). After each bleaching stage, washing was performed on a 230mesh screen, using tap water to reach a neutral $\mathrm{pH}$ of 7. The bleached pulp was refined using a laboratory double-disc refiner and a Valley beater according to TAPPI standard method (T $200 \mathrm{sp}-96$ ).

The CS suspension $(0.5 \%$ consistency $)$ was prepared and poured in an Erlenmeyer flask and the total volume was brought to $100 \mathrm{~mL}$ using distilled water. After stirring, the Erlenmeyer flask was covered with aluminum foil to prevent evaporation, then it was placed on a heater and the temperature was gradually increased to $90{ }^{\circ} \mathrm{C}$ for 30 minutes, while stirring. Afterwards, the suspension was kept at this temperature for another $30 \mathrm{~min}$. To prevent viscosity and consistency changes, the starch suspension was prepared each day and used freshly.

A $0.05 \%$ concentration of CPAM suspension was prepared according to an in-house developed method and it was used as CNF retention aid in the pulp slurry. ${ }^{21}$ In order to make handsheets with the addition of nanofiber and CPAM, the $0.3 \%$ consistency pulp suspension was stirred at $1500 \mathrm{rpm}$ for 60 seconds, then, the nanofiber suspension with the same consistency was added and stirred for another 60 seconds. CPAM was gently added afterwards and then stirred at $2000 \mathrm{rpm}$ for one minute to deflocculate the suspension.

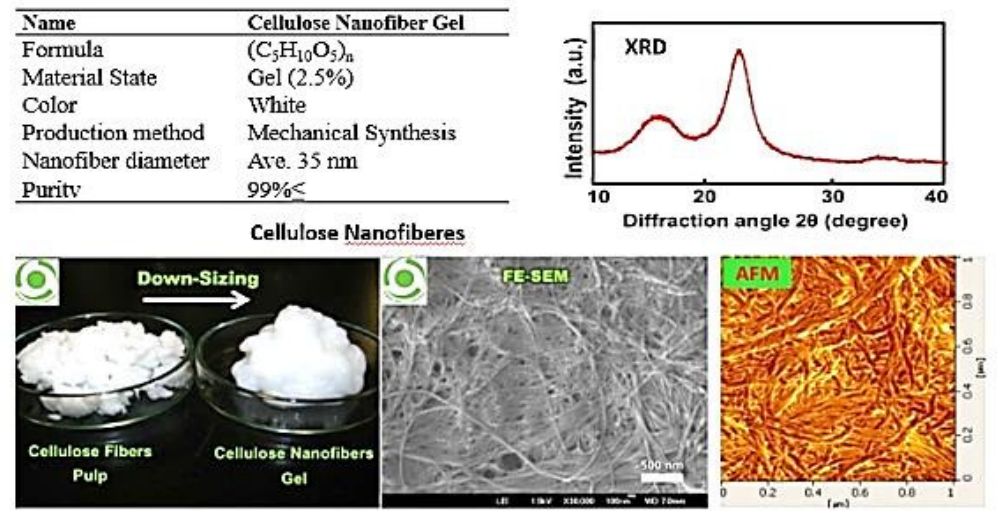

Figure 1: Cellulose nanofiber gel specifications (Nano Novin Polymer Company, 2017)

Table 1 
PEJMAN REZAYATI CHARANI and MOHAMMAD HADI MORADIAN

Bleaching condition of brown Kraft pulp

\begin{tabular}{cccccc}
\hline Interval & Chemicals & Time $(\mathrm{min})$ & Chem. ratio & Temp. $\left({ }^{\circ} \mathrm{C}\right)$ & Solid conc. (\%) \\
\hline $\mathrm{E}$ & $\mathrm{NaOH}$ & 120 & $1: 4$ & 60 & 10 \\
$\mathrm{H}$ & $\mathrm{NaOCL}$ & 120 & $1: 1$ & 60 & 10 \\
\hline
\end{tabular}

Table 2

Composition of handsheets

\begin{tabular}{cccccc}
\hline Run & $\begin{array}{c}\text { Mixed } \\
\text { hardwood pulp (\%) }\end{array}$ & $\begin{array}{c}\text { Long fiber } \\
(\%)\end{array}$ & $\begin{array}{c}\text { CNFs } \\
(\%)\end{array}$ & $\begin{array}{c}\text { CS } \\
(\%)\end{array}$ & $\begin{array}{c}\text { CPAM } \\
(\%)\end{array}$ \\
\hline 1 & 100.00 & - & - & - & - \\
2 & 90.00 & 10.00 & - & - & - \\
3 & 85.00 & 15.00 & - & - & - \\
4 & 80.00 & 20.00 & - & - & - \\
5 & - & 100.00 & - & - & - \\
6 & 99.70 & - & - & 0.30 & - \\
7 & 99.50 & - & - & 0.50 & - \\
8 & 99.30 & - & - & 0.70 & - \\
9 & 99.00 & - & - & 1.00 & - \\
10 & 97.00 & - & 3.00 & - & - \\
11 & 99.07 & - & - & - & 0.03 \\
12 & 99.05 & - & - & - & 0.05 \\
13 & 96.50 & - & 3.00 & 0.50 & - \\
14 & 96.30 & - & 3.00 & 0.70 & - \\
15 & 96.07 & - & 3.00 & - & 0.03 \\
16 & 96.05 & - & 3.00 & - & 0.05 \\
17 & 96.48 & & 3.00 & 0.50 & 0.02 \\
18 & 96.47 & - & 3.00 & 0.50 & 0.03 \\
\hline
\end{tabular}

Handsheets were made in a laboratory sheet former according to the TAPPI standard method (T $205 \mathrm{sp}-$ 02). Several series of handsheets were made with different amounts of CNFs, CPAM and CS (Table 2).

To make handsheets with the addition of nanofiber and CS, the same method was used, with the difference that the blending speed was kept at $1500 \mathrm{rpm}$ after adding CS. To make handsheets with the addition of nanofiber, CS and CPAM, the nanofiber was added and stirred for $60 \mathrm{~s}$. Then, CS was added and mixed for another $60 \mathrm{~s}$, while maintaining the stirring at 1500 rpm. Later on, CPAM was gently added and blended at $2000 \mathrm{rpm}$ for one minute. The pulp freeness was measured according to TAPPI standard method (T 227 om-04), as well as paper thickness (T 411 om-05), paper basis weight (T 410 om-02), and breaking length properties (T $404 \mathrm{om}-92$ ).

\section{RESULTS AND DISCUSSION Bleached pulp}

Brown pulp made of hardwood, with the freeness of $550 \mathrm{~mL} \mathrm{CSF}$, was bleached and was used to make $60 \mathrm{~g} / \mathrm{m}^{2}$ handsheets, which showed brightness of 75. It is expected that some bleached pulp fines and carbohydrates would pass through the 230 mesh screen during washing, and for this reason, the final freeness of the pulp was measured as $415 \mathrm{~mL} \mathrm{CSF}$.

\section{Influence of long fiber pulp on breaking length}

According to Figure 2, as the percentage of long fiber pulp increased in the bleached Kraft pulp, the handsheet breaking length increased from 2.05 to $7.05 \mathrm{~km}$. It should be noted that the basic breaking length amount in this research was low and it increased when the long fibers (15\%) were added. It was observed that the addition of $15 \%$ long fiber to the original hardwood pulp made $40 \%$ improvement in handsheet breaking length.

\section{Influence of cationic starch on breaking length}

According to Figure 3, adding 1\% CS to the basic pulp increased the handsheet breaking length more than that of the $15 \%$ long fibers. Accordingly, adding $0.5,0.7$ and $1 \%$ CS increased the handsheet breaking length to 25,41 and $47 \%$, respectively. The addition of more than $1 \% \mathrm{CS}$ is not recommended because of the downstream process problems it may cause. For example, Pars Paper Mill reported some stickiness 
and starch sediments in the headbox, which made starch bubbles on the wet paper, holes, and finally led to paper breaking during production. ${ }^{27}$ Generally, to prevent these problems, less than $1 \%$ starch is suggested to be added at the wet-end part in the mentioned mill. However, the suitable amount of CS addition depends on its degree of substitution too. In this study, some stickiness of fibers to the net and the cylinder of the handsheet machine was observed when the more than $1 \%$ CS was used. Meanwhile, a lower amount of CS was unable to maintain the paper properties strong enough. For this reason, other additives were applied.

\section{Influence of CNFs and CS on breaking length}

CNFs have been added in amounts of $1-6 \%$ to reinforce different papers. ${ }^{7,8}$ In this study, $3 \%$ $\mathrm{CNFs}$ and 0.5 and $0.7 \% \mathrm{CS}$ were added to pulp to eliminate process problems, while strengthening paper. Figure 4 shows the result of using CNFs together with CS. It is shown that adding 3\% CNFs improved the breaking length of handsheets by about $25 \%$, comparing with the control sample with no additives. It is necessary to retain

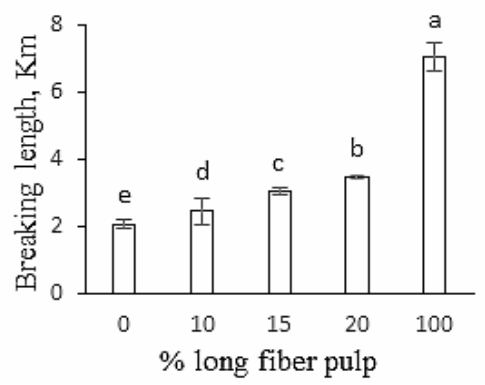

Figure 2: Influence of long fibers on handsheet breaking length

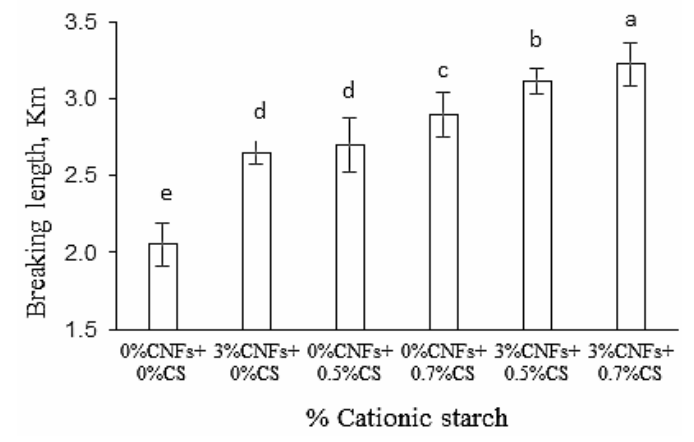

Figure 4: Influence of cationic starch (CS) and cellulose nanofibers (CNFs) on handsheet breaking length nanofibers with cationic aids, such as starch or polyacrylamide, to the pulp slurry. As a result of using a double system of CNFs and CS, the handsheet breaking length increased (Table 2, run 13 and 14). It was observed that adding $3 \%$ CNFs together with 0.5 and $0.7 \%$ CS increased the handsheet breaking length by $15-20 \%$, compared to those handsheets made with single additives. Moradian et al. reported a positive influence of starch and CNFs in improving paper breaking length, having attained the equivalent breaking length to the case when $15 \%$ long fiber was used. $^{29}$

\section{Influence of CNFs and CPAM on breaking length}

Generally, adding a little CPAM to the pulp suspension can help the fines retain in the paper and increase the fiber bonding and paper breaking length. According to Figure 5, adding 0.03\% CPAM to the pulp suspension improved handsheet breaking length by $22 \%$. Adding more CPAM (0.05\%) also improved the breaking length as much as by $20 \%$.

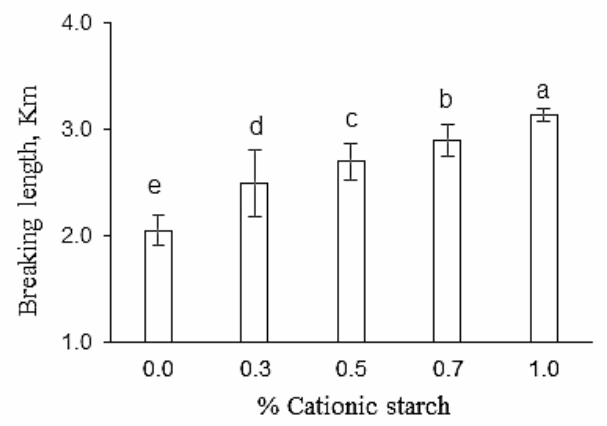

Figure 3: Influence of cationic starch on handsheet breaking length

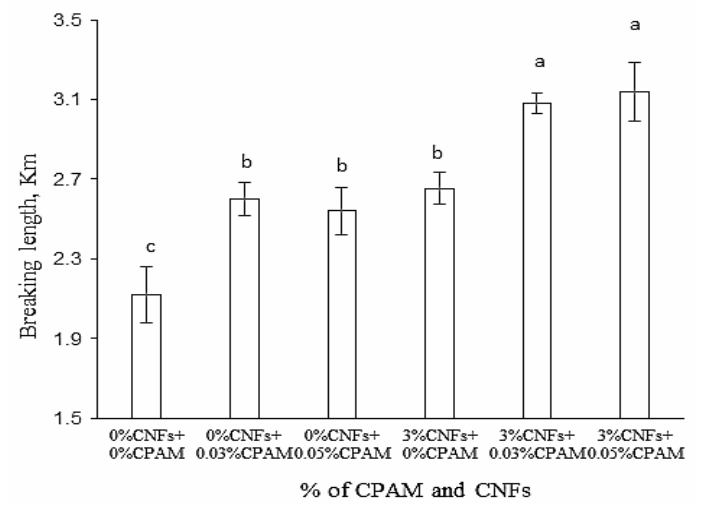

Figure 5: Influence of cationic polyacrylamide (CPAM) and cellulose nanofibers (CNFs) on handsheet breaking length 


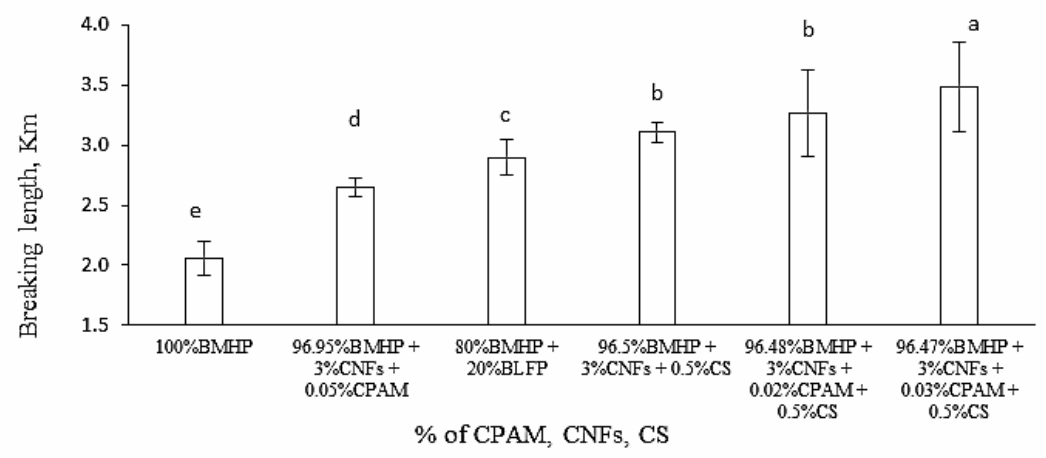

Figure 6: Influence of cationic starch (CS), polyacrylamide (CPAM) and cellulose nanofibers (CNFs) on handsheet breaking length

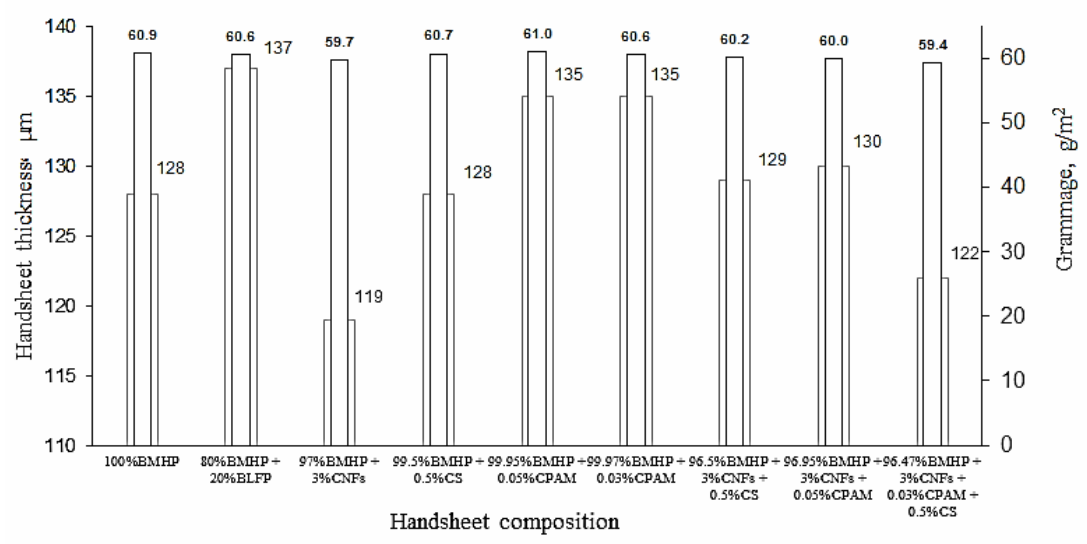

Figure 7: Influence of cationic starch (CS), polyacrylamide (CPAM) and cellulose nanofibers (CNFs) on handsheet thickness

The suitable amount of CPAM addition depends on the pulp type, its fine content, and the electrical charge of the suspension. Scientifically, using too much CPAM increases the cationic load of the system and creates flocks, which are hard to deflocculate by shear forces. In this condition, paper formation is disturbed and there are regions with weak formation, leading to lower breaking length of paper. The polymer retains CNFs and increases the paper breaking length. As shown in Figure 5 , by using $3 \%$ nanofiber together with 0.03 and $0.05 \%$ CPAM, breaking length increased by 45 and $48 \%$, respectively.

\section{Influence of CNFs, CS and CPAM on breaking length (triple system)}

The effects of using the triple system of CNFs, CS and CPAM (Table 2, run 17 and 18) were investigated and the results are shown in Figure 6. Since starch and polyacrylamide were both cationic and too much cation creates negative influences on paper strength, the optimum amount of polymer should be less than the amount when there is no CS. According to Figure 4, adding 3\% CNFs together with $0.5 \%$ CS and $0.03 \%$ CPAM increased the handsheet breaking length by 59\%, which was the same as when adding $20 \%$ long fibers to the basic pulp, while keeping the starch and CNFs amounts to the minimum possible. Thus, the triple system of CNFs, CS and CPAM can be considered as a good alternative to replace long fibers in papermaking, as well as obtain better results compared to those of a double system.

\section{Influence of different additives on paper caliper}

Figure 7 shows the caliper and the basis weight of the handsheets made with the addition of long fibers, CNFs, CS and CPAM to the pulp. 
Softwood long fibers are coarser than hardwood fibers, which made pulp with higher freeness and thereby, thicker papers. Adding CNFs to the pulp decreases paper thickness because this material is made up of very tiny particles stuck in fiber network pores, while a part of it could pass through the wire and get lost, especially when retention aids are not used. Therefore, a decrease in caliper and basis weight was expected. In other words, when CNFs are added to pulp, a higher amount of solid should be taken, to achieve the same basis weight of paper. CS retains fines, which improves paper grammage. CPAM generally retains pulp fines during drainage and makes flocks in the pulp. This feature increased the handsheet grammage, as shown in Figure 7. Besides, these flocks need to be broken to make suitable paper formation. However, handsheets made with the treatment of CPAM showed the highest thickness among the samples with the same paper grammage. When applying three additives: CNFs, CS and CPAM, the paper thickness increased.

\section{CONCLUSION}

Generally, adding long fiber, cellulose nanofiber, cationic starch and polyacrylamide to short fiber pulp improves paper properties. However, each one has its own limitations and drawbacks in a production system. This study aimed to assess the possibility of using CNFs, cationic starch and polyacrylamide, or as a combination, to substitute long fibers in papermaking from bleached hardwood Kraft pulp. As opposed to long fibers, these ingredients (CS, CNFs and CPAM) are locally available. As a result, using a little amount of CS (1\%) at a lab scale produced a strong paper, but because of some process problems, industries may not consider it. Moreover, using a combination of starch and CNFs as a double system showed a good opportunity to replace a 15\% long fiber fraction in the pulp, while keeping paper breaking length at the same level. In addition, using a triple system of cellulose nanofiber, cationic starch and polyacrylamide increased paper breaking length to the level achieved when using more than $20 \%$ long fiber in the pulp suspension. This triple system also made it possible to use a lower amount of cellulose nanofiber, which is economically favorable, and less cationic starch to minimize process problems during paper production.
ACKNOWLEDGEMENT: Financial support for this project ("Investigation on paper properties improvement of bleached Kraft hardwood pulp using cellulosic nanofibers" contract No. 6.24670) was provided by the Behbahan Khatam Alanbia University of Technology, which is appreciated.

\section{REFERENCES}

1 M. Tajik, H. J. Torshizi, H. Resalati and Y. Hamzeh, Carbohyd. Polym., 194, 1 (2018), https://doi.org/10.1016/j.carbpol.2018.04.026

2 T. Li, J. Fan and W. Chen, Carbohyd. Polym., 149, 20

(2016),

https://doi.org/10.1016/j.carbpol.2016.04.082

T. Kurihara and A. Isogai, Cellulose, 22, 499 (2015), https://doi.org/10.1007/s10570-014-0478-x

4 M. Wu, W. Lv, F. Wang Z. Long, J. Chen et al., Cellulose Chem. Technol., 52, 43 (2018), http://www.cellulosechemtechnol.ro/pdf/CCT12(2018)/p.43-49.pdf

5 A. Ghasemian, M. Ghaffari and A. Ashori,

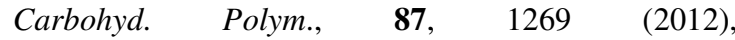
https://doi.org/10.1016/j.carbpol.2011.09.010

6 D. Eklund and T. Lindström, "Paper Chemistry An Introduction", DT Paper Science Publications, Grankulla, Finland, 1991, pp. 160-164, https://books.google.com/books/about/Paper_Chemistr y.html?id=kwkRAwAACAAJ

P. R. Charani, M. Dehghani-Firouzabadi, E. Afra, Å. Blademo, A. Naderi et al., Cellulose, 20, 2559 (2013), https://doi.org/10.1007/s10570-013-9998-z

S. R. Jafari Petroudy, K. Syverud, G. ChingaCarrasco, A. Ghasemain and H. Resalati, Carbohyd. $\begin{array}{llll}\text { Polym., } & 99, & 311 & \text { (2014), }\end{array}$ https://doi.org/10.1016/j.carbpol.2013.07.073

9 A. M. Adel, A. A. El-Gendy, M. A. Diab, R. E. Abou-Zeid, W. K. El-Zawawy et al., Ind. Crop. Prod., 93, 161

(2016),

https://doi.org/10.1016/j.indcrop.2016.04.043

10 S. H. Osong, S. Norgren and P. Engstrand, Cellulose, 23, 93 (2016), https://doi.org/10.1007/s10570-015-0798-5

11 Q. Tarrés, N. Pellicer, A. Balea, N. Merayo, C. Negro et al., Int. J. Biol. Macromol., 105, 664 (2017), https://doi.org/10.1016/j.ijbiomac.2017.07.092

12 A. Dufresne, Curr. For. Rep., 5, 76 (2019), https://doi.org/10.1007/s40725-019-00088-1

13 V. Grigoriev, K. Strengell, M. Virtanen and M. Hietaniemi, Strength chemistry for board and tissue production: Scientific outlook and end applications, http://www.kemira.com/Materials/strength-chemistrypapfor-2012-en-kemira.pdf

14 T. Linström, L. Wågberg and T. Larsson, Report: On the nature of joint strength in paper, http://www.innventia.com/documents/rapporter/stfipackforsk\%20report\%2032.pdf 


\section{PEJMAN REZAYATI CHARANI and MOHAMMAD HADI MORADIAN}

15 V. Goodarzi, S. H. Jafari, H. A. Khonakdar and J. Seyfi, J. Polym. Res., 18, 1829 (2011), https://doi.org/10.1007/s10965-011-9590-X

16 S. Y. Yoon and Y. Deng, J. Appl. Polym. Sci., 100, 1032 (2006), https://doi.org/10.1002/app.23007

17 J. Kuusisto and T. C. Maloney, Ind. Crop. Prod., 83, 294

https://doi.org/10.1016/j.indcrop.2016.01.026

18 D. Glittenberg, Tappi J., 76, 215 (1993), https://www.tappi.org/publications-standards/tappijournal/home/

19 A. Swerin, Colloid. Surface A, 133, 279 (1998), https://doi.org/10.1016/S0927-7757(97)00212-4

20 J. Laine, in: "Papermaking Science and Technology", Book 4: Papermaking Chemistry, edited by R. Alén, Paperi ja Puu Oy, Helsinki, Finland, 2007, pp. $28-55$,

https://www.puunjalostusinsinoorit.fi/shop/vol-4papermaking-chemistry/

${ }^{21}$ E. A. Hassan, M. L. Hassan and K. Oksman, Wood Fiber Sci., 43, $76 \quad$ (2011), https://wfs.swst.org/index.php/wfs/article/view/1062

22 M. E. Vallejos, F. E. Felissia, M. C. Area, N. V. Ehmana, Q. Tarrés et al., Carbohyd. Polym., 139, 99 (2016), https://doi.org/10.1016/j.carbpol.2015.12.004

23 T. Arndt, G. Meinl and K. Erhard, Papiripar Special issue for the COST E54, 6, 265 (2008), http://www.epa.hu/00800/00863/00036/pdf/papiripar_ 2008_06.pdf\#page $=63$
24 K. Missoum, N. Belgacem and M. Krouit, in Procs. Tappi Nanotechnology Conference for the Forest Product Industry, Espoo, Finland, 2010, pp. 334-359, https://imisrise.tappi.org/TAPPI/Products/10/NAN/10 NANOCD.aspx

25 S. Boufi, I. González, M. Delgado-Aguilar, Q. Tarres, M. À. Pèlach et al., Carbohyd. Polym., 154, 151

(2016),

https://doi.org/10.1016/j.carbpol.2016.07.117

${ }_{26}$ Y. Zou and J. S. Hsieh, in Procs. International Conference on Nanotechnology for the Forest Products Industry, Knoxville, TN, June 13-15, 2007, pp.

$1-13$, https://imisrise.tappi.org/TAPPI/Products/07/NAN/07 NAN16.aspx

27 T. Taipale, M. Österberg, A. Nykänen, J. Ruokolainen and J. Laine, Cellulose, 17, 1005 (2010), https://doi.org/10.1007/s10570-010-9431-9

28 D. S. Rende and M. D. Breslin, U.S. Patent $4,657,946$

(1987), https://patents.google.com/patent/US4657946A/en

${ }^{29}$ M. H. Moradian, P. R. Charani and M. A. Saadatnia, J.F.W.P., $\quad$ 69, $603 \quad$ (2016), https://doi.org/10.22059/JFWP.2016.59898

30 Y. Xia, G. Yang, J. Chen and Z. Lin, BioResources, 14 , 7041 (2019),

https://ojs.cnr.ncsu.edu/index.php/BioRes/article/view/ BioRes_14_3_7041_Xia_Cellulose_ation/7023 